\title{
Characterization of mouse spermatogonia by transmission electron microscopy
}

\author{
H. Chiarini-Garcia ${ }^{1}$ and L. D. Russell ${ }^{2+}$ \\ ${ }^{1}$ Laboratory of Cellular Biology, Department of Morphology, Federal University of Minas \\ Gerais, Belo Horizonte 31270-901, Brazil; and ${ }^{2}$ Department of Physiology, Southern Illinois \\ University, School of Medicine, Carbondale, IL 62901, USA
}

Characteristics of the various type A, intermediate (In) and $B$ spermatogonia were determined in $\mathrm{C} 57 \mathrm{BL} / 6 \mathrm{~J}$ mice using transmission electron microscopy. Spermatogonia were photographed at all stages of the cycle of the seminiferous epithelium. Over 450 images were taken. Spermatogonia could be classified into $A_{s}, A_{p r}, A_{a l}, A_{1}$ cells, $A_{2}$ cells, $A_{3}$ cells, $A_{4}$ cells, intermediate type and type $B$ cells primarily on the basis of nuclear and nucleolar characteristics. The most primitive spermatogonia $\left(A_{s}, A_{p r}, A_{a l}\right)$ had mottled chromatin; $A_{1}$ cells contained homogeneously finely

\section{Introduction}

The diploid germ cells that initiate spermatogenesis, the spermatogonia, have been the least studied of all the germ cells. Most studies have examined the kinetics of spermatogonia from stem cells to their division into spermatocytes using whole-mount techniques in which clones of spermatogonia are visible and the cell type can be identified by association with a particular stage of the seminiferous epithelium. The number of cells has also been useful to identify cells by their intercellular bridges and number of cells in a clone (Huckins and Oakberg, 1978; de Rooij and Russell, 2000). It is generally now appreciated that spermatogonia undergo 9-11 divisions before entering meiosis. Studies of spermatogonia have mainly examined their behaviour in whole mounted seminiferous tubules after, for example, irradiation (van Beek et al., 1984), vitamin A depletion (van Pelt et al., 1995) or transplantation (Nagano et al., 1999). There is considerable information about various other types of germ cell, such as spermatocytes and spermatids, but because spermatogonia are thought to 'look similar', most investigators still view the spermatogonia as a morphologically homogeneous population.

In mice and rats, the most primitive cell is an $A_{s}$ spermatogonium that functions as the stem cell (de Rooij, 2001). It is not connected to other spermatogonia by intercellular bridges and is characterized as a 'single' or 'isolated' cell $\left(A_{s}\right)$. The $A_{s}$ cells divide, but maintain a telophase connection known as the intercellular bridge. The $A_{p r}$ (paired) cells,

\section{${ }^{\dagger}$ Deceased}

Email: chiarini@icb.ufmg.br granular chromatin throughout the nucleus; $A_{2}, A_{3}, A_{4}$ and intermediate type spermatogonia had progressively increasing amounts of chromatin encrusting the nuclear envelope; type B spermatogonia had less heterochromatin along the nuclear envelope, although the particles were more dense and rounded than in intermediate type spermatogonia. Mitochondrial size and position of Golgi complexes varied in different types of spermatogonia. These data show that types of spermatogonia can be differentiated such that these characteristics can be used in functional studies.

formed from an $\mathrm{A}_{\mathrm{s}}$ spermatogonium, divide to form longer chains of interconnected cells called $\mathrm{A}_{\mathrm{al}}$ (aligned) spermatogonia. The divisions up to the $A_{a l}$ stage may occur at any time during the cycle of the seminiferous epithelium. Once the chains of $A_{a l}$ cells reach about 16 cells, they transform at a predictable time during the spermatogenic cycle to $A_{1}$ cells. $A_{1}$ cells divide to form $A_{2}$ cells, and $A_{2}$ cells divide to form $A_{3}$ cells, which divide to form $A_{4}$ cells. The $A_{4}$ cells divide to form intermediate type spermatogonia, which divide to form type $B$ spermatogonia. All divisions after $A_{1}$ occur at predictable stages of the cycle of the seminiferous epithelium (de Rooij, 1998). The chain length of spermatogonia increases progressively with each cell division.

There is evidence that there may be morphological differences in some of the type A spermatogonia visible using a light microscope (Clermont and Bustos-Obregon, 1968; Oakberg, 1971; Huckins and Oakberg, 1978). More recently, Chiarini-Garcia and Russell (2001) used high resolution light microscopy to define the characteristics of many of the types of mouse spermatogonial cell. The ability to distinguish types of spermatogonial cell allows spermatogonia to be studied functionally (Chiarini-Garcia et al., 2001). In the present study, light microscopic observations of spermatogonia have been extended using an electron microscope. Our observations relating to the fine structural differences in the various types of spermatogonia are presented.

\section{Materials and Methods}

Animals, tissue collection and processing

Four adult C57BL/6J mice, $27.80 \pm 0.52 \mathrm{~g}$ body weight, were obtained from Jackson Labs (Bar Harbor, ME). The 
maintenance of the animals was in full compliance with the standard laboratory animal care protocols approved by Institutional Animal Care and Use Committee (IACUC). Mouse testes were perfusion-fixed according to the technique of Sprando (1990). In brief, each animal was given heparin $15 \mathrm{~min}$ before perfusion. Saline was perfused initially to clear the blood from the testis followed by $5 \%(\mathrm{w} / \mathrm{v})$ glutaraldehyde ( $\mathrm{pH} 7.2-7.4)$ in 0.05 mol sodium cacodylate buffer $\mathrm{I}^{-1}$. After a glutaraldehyde perfusion of approximately $20 \mathrm{~min}$, the testes were excized, weighed $(104 \pm 1.36 \mathrm{~g}$; $n=8$ ) and cut into $0.5 \mathrm{~mm}$ slabs by perpendicular sectioning. The slabs were cut into approximately $2 \mathrm{~mm}$ (length $\times$ width) portions and embedded such that crosssections of seminiferous tubules would be obtained when the samples were cut into sections. After an overnight fixation of the diced slabs, the tissues were washed in three changes of buffer, post-fixed in an osmium:ferrocyanide mixture (Russell and Burguet, 1977), dehydrated, embedded in epoxy resin and cut into sections $(1 \mu \mathrm{m}$ thickness) for light microscopy.

\section{Electron micrograph study}

Tissues from four animals used in a previous study were used again in the present study (Chiarini-Garcia and Russell, 2001). Embedded blocks were trimmed to reflect a random collection of stages of the cycle of the seminiferous epithelium. Sections showing silver-gold to gold interference colours were made with a diamond knife and mounted on celloidincoated slot grids. All type A spermatogonia displaying nuclei less mature than $A_{3}$ spermatogonia were photographed in the 12 stages of the cycle of the seminiferous epithelium. As there were numerous $A_{3}, A_{4}$, type $B$ and intermediate type spermatogonia within the epithelium, only random images of these cells were photographed. Images displaying grazing sections of the nucleus were not photographed.

The staging criteria used to identify spermatogonia were those of Oakberg (1956), as modified and depicted by Russell et al. (1990). In particular, the 'stage range' diagram of Russell et al. (1990) was used to determine the beginning and end of each stage. More than 35 micrographs of type A spermatogonia were taken with a Hitachi $500 \mathrm{H}$ Electron Microscope (Hitachi Corporation, Tokyo) at each stage. The magnification range of the negatives was $\times 2000-4000$ original size.

Images were mounted on the wall of a room. Using criteria and the general concepts developed for light microscope study (Chiarini-Garcia and Russell, 2001), spermatogonia were categorized by a single worker into type of cell $\left(A_{s}\right.$ to $A_{a l}, A_{1}, A_{2}, A_{3}, A_{4}$, intermediate type and type $B$ ) and stage without any prior knowledge of the stage from which the micrograph was taken. After preliminary classification, the stage at which the micrograph was taken was added and the accuracy of the investigator was tested using only cells from stages in which the cell type was known to occur. After providing criteria for a particular type of cell, the spermatogonia were categorized for all stages of the cycle.

\section{Stereological studies}

Measurements of subcellular organelles and determination of position of organelles were performed. Transversely sectioned mitochondria that showed spherical profiles were measured from micrographs using the smallest dimension of the cross-section or the smallest diameter in a slightly oblique section, using a scale lupe. All measurements of mitochondria were pooled from a particular type of cell or grouping to yield a mean mitochondrial diameter. Thirtytwo to sixty-three diameters were measured for each type of spermatogonia.

The position of the centre of the Golgi complex was also determined from data pooled from all animals for individual types of cell. The centre of the nucleus was considered as the centre of a clock and 12 clock numbers were assigned radially around the nucleus to determine the Golgi position. The position of each Golgi complex was recorded as a clock hour number. As the orientation of the tubule with respect to the rete was not known, horizontal mirror image dimensions of the clock were considered equivalent, for example 3 o'clock and 9 o'clock were equivalent.

A digitizer was used to determine the length of the contact of various types of spermatogonia with the basal lamina. Only cells that showed their entire contact in the micrograph were measured.

\section{Statistical analysis}

Data are presented as mean \pm SEM. Statistical analyses were performed by ANOVA and Student's $t$ test for multiple comparison among means. Differences were considered significant at $P<0.05$.

\section{Results}

All but one spermatogonium that was photographed was well fixed. This single poorly fixed spermatogonium had darker than usual cytoplasm and this feature was regarded as an artefact of fixation, as the mitochondria were swollen.

After images were printed, the light microscope criteria defined previously were used to make an initial attempt to identify specific types of cell by the other investigator. The initial attempt to identify cells was $85 \%$ accurate when compared with the final assignment of type of cell that was made using known staging criteria. Even with knowledge of the stage from which a particular cell was found, the identity of some cells remained in question because cells of different types are found within a particular stage owing to mitotic divisions in that stage. Cells in question were not used in the subsequent morphological and quantitative analyses below, as they were excluded from the initial assessment presented above.

A feature not reported previously for any type A spermatogonia was the presence of multivesicular bodies (Fig. $1 \mathrm{a}-\mathrm{d})$. Few internalized vesicles were present in any of the multivesicular bodies. Multivesicular bodies were always located in the juxta-Golgi region. Although multivesicular 

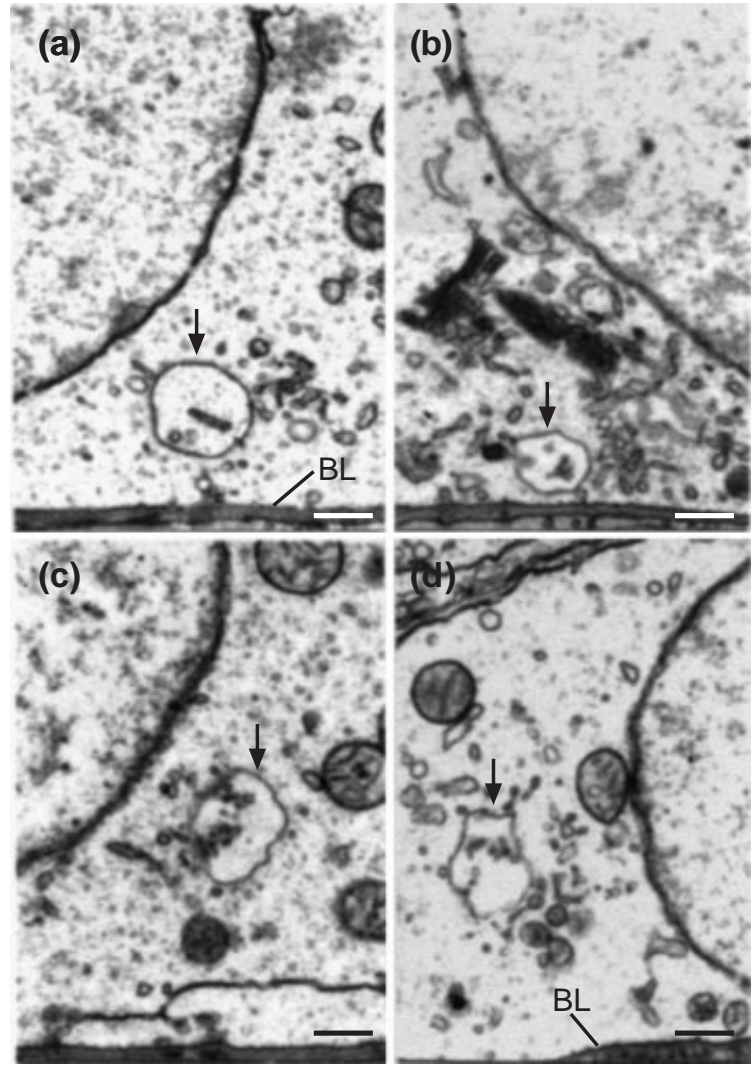

Fig. 1. Multivesicular bodies in mouse spermatogonia. (a) Stage I, $(b, c)$ stage XII and (d) stage VI spermatogonia. Spermatogonia show a large vesicular element with sparse, small, vesicles contained within. These were frequently observed near the Golgi apparatus and were thought to be multivesicular bodies (arrows). BL: basal lamina. Scale bars represent $0.5 \mu \mathrm{m}$.

bodies were present, lysosomes, expected to be associated with multivesicular bodies, were not detected.

\section{$A_{s}, A_{p r}, A_{a l}$ spermatogonia}

The nuclei of this combined group of spermatogonial cells displayed foci of dense heterochromatin flecks (Fig. $2 a, b)$. Moderately dense heterochromatin flecks, measuring no more than $0.23 \pm 0.02 \mu \mathrm{m}$ across, were larger than heterochromatin flecks in any of the other more advanced type A spermatogonia. The nucleus had a mottled appearance with the moderately dense heterochromatin forming the denser regions and virtually no heterochromatin in the lighter regions. No intranuclear vacuoles were noted, as was reported in a recent light microscope study (ChiariniGarcia and Russell, 2001) and shown previously by electron microscopy (de Rooij, 1973). The nucleolus appears to be reticulated tightly; the reticulation is produced by the folding of the pars fibrosa. Mitochondrial profiles measured $0.57 \pm 0.01 \mu \mathrm{m}$ across (Fig. 3). The Golgi apparatus was located $55.4 \%$ of the time in the basal, basolateral and lateral aspects of the cytoplasm, but could be found in any position (Fig. 4).
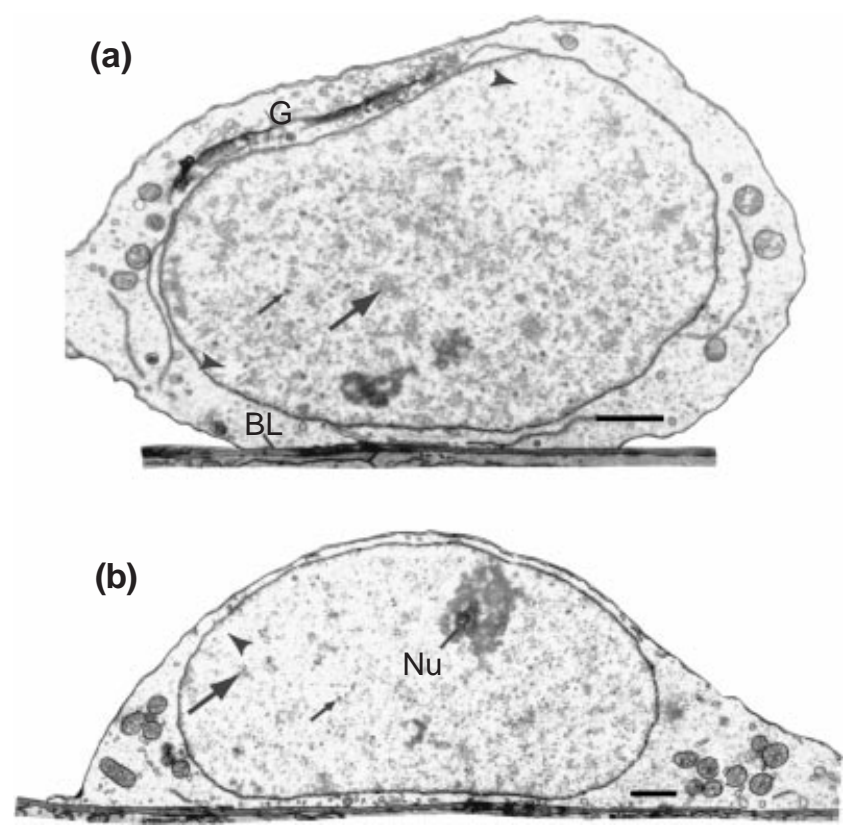

Fig. 2. $A_{s}, A_{p r}$ and $A_{a l}$ mouse spermatogonia. $(a, b)$ The nucleus shown contains a mottled appearance with dark speckles of heterochromatin (small arrow), moderately dense heterochromatin measuring $\leqslant 0.23 \mu \mathrm{m}$ across (large arrow) and rarefied areas (arrowheads). (a) The Golgi apparatus (G) is positioned away from the basal lamina (BL) at the apical aspect of the cell. (b) A portion of a small compact nucleolus $(\mathrm{Nu})$ is visible. (a) Stage II and (b) stage VI. Scale bars represent $1 \mu \mathrm{m}$.

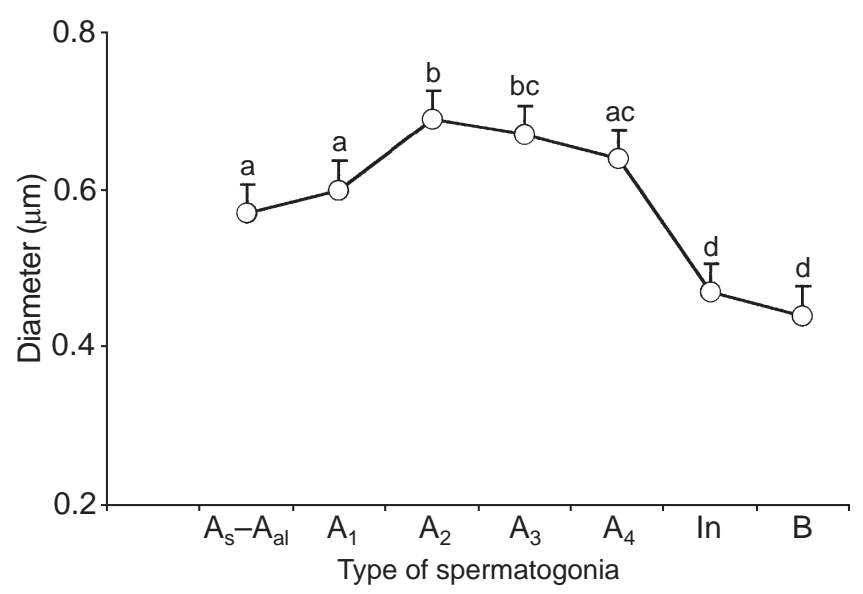

Fig. 3. Cross-sectional diameter of mitochondria of various types of mouse spermatogonia. ${ }^{a-d}$ Different letters indicate significant differences among groups $(P<0.05)$.

\section{$A_{s}, A_{p r}, A_{\text {al subtype } 2}$ spermatogonia}

A small percentage of all spermatogonia were of the $A_{S}$ to $A_{a l}$ lineage and were morphologically different from most of the cells in the $A_{s}$ to $A_{a l}$ lineage. The $A_{s}$ to $A_{a l}$ subtype 2 cells were named for their apparent counterpart in the study of Chiarini-Garcia and Russell (2001). The nucleus of these cells was ovoid and moderately dense chromatin 

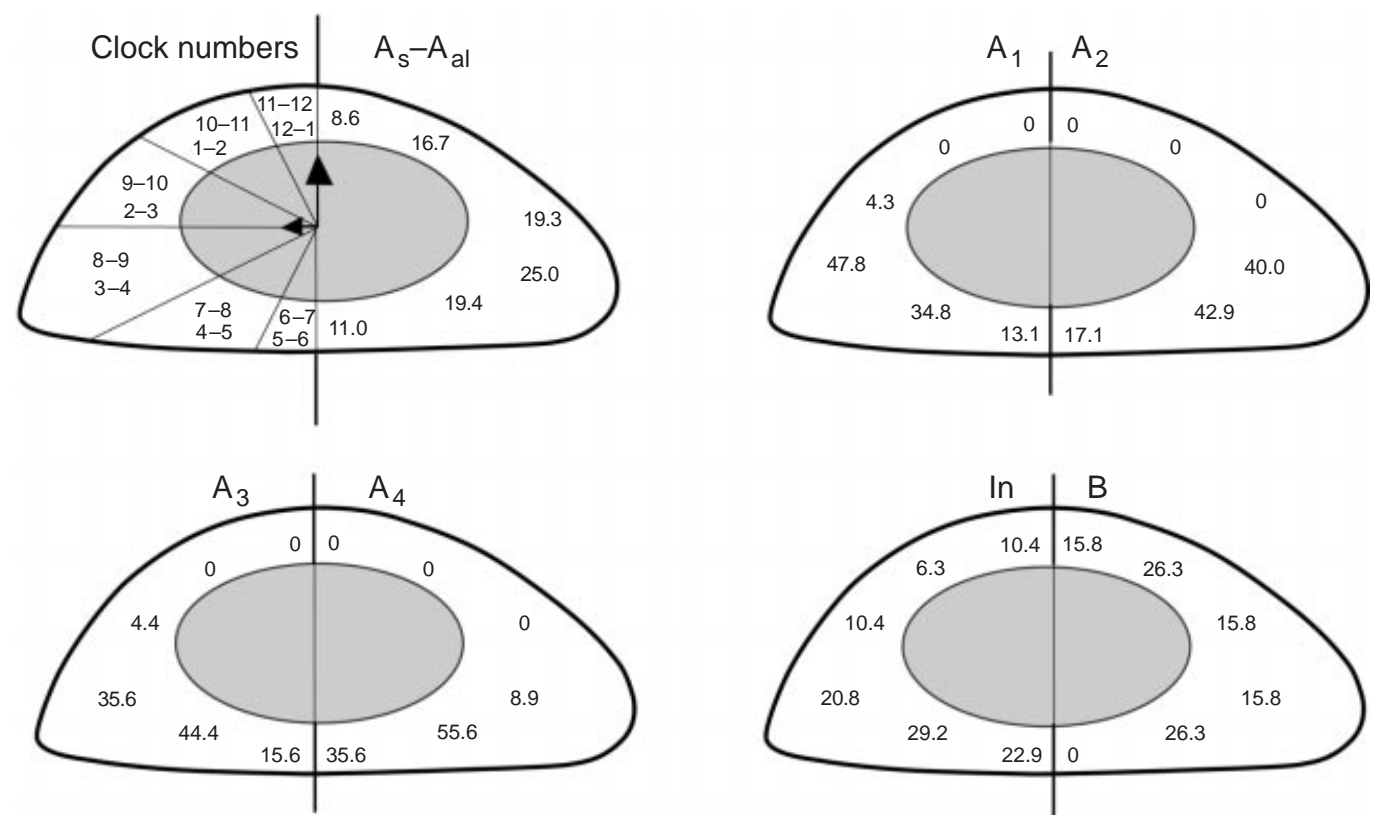

Fig. 4. Position of the Golgi apparatus of mouse spermatogonia presented as a percentage of the total cells of a particular type. Twelve compartments have been designated radially around the cell from a central position in the nucleus as would be found in a clock. As the orientation of the tubule and the section is not known with respect to the rete, the percentage values for each type of cell are plotted in one-half of the drawing. They correspond to the values of both the left and right sides.

was highly mottled against an electron translucent background (Fig. 5a,b). The mottling was more pronounced in $\mathrm{A}_{\mathrm{al}}$ subtype2 cells $(0.53 \pm 0.02 \mu \mathrm{m})$ than in any other cells of the $\mathrm{A}_{\mathrm{s}}$ to $\mathrm{A}_{\mathrm{al}}$ lineage $(0.23 \pm 0.02 \mu \mathrm{m}, P<0.05)$. Very little heterochromatin lined the nuclear envelope. Small, dense flecks of heterochromatin were present and were similar to those of $A_{s}, A_{p r}$ and $A_{a l}$ cells. The pars fibrosa of the nucleolus was reticulated and the nucleolus was compacted (Fig. 5c). Too few cells were encountered to determine the position of the Golgi apparatus in this subpopulation of cells.

\section{$A_{a l}$ to $A_{1}$ transition spermatogonia}

In late stage VII and VIII, numerous forms of spermatogonia were observed that were transitional between the type $A_{s}, A_{p r}, A_{a l}$ spermatogonia and $A_{1}$ spermatogonia. There were numerous gradations in morphology in these transitional forms that contained characteristics of both cell types. A single example is shown (Fig. $5 \mathrm{~d}$ ).

\section{$A_{1}$ spermatogonia}

No heterochromatin lined the nuclear envelope of type $A_{1}$ spermatogonia (Fig. 6a,b). The nuclear matrix was uniformly finely granular. Mitochondrial cross-sections were $0.60 \pm 0.01 \mu \mathrm{m}$ in diameter (Fig. 3). The Golgi apparatus lies in the basal lateral region of the cell $95.7 \%$ of the time and is observed rarely in the apical portion of the cell (Fig. 4). The nucleolus is compact and the pars fibrosa is slightly more reticulated than the nucleolus of cells of the $A_{s}, A_{p r}$ $A_{a l}$ group (Fig. 6 a,b).

\section{$A_{2}$ spermatogonia}

The nuclear matrix of $A_{2}$ spermatogonia had denser chromatin than in $A_{1}$ cells (Fig. 6c,d). There were more areas in the nucleus that appeared finely mottled than in the precursor $\mathrm{A}_{1}$ cells. Small, shallow flecks of chromatin lined the nuclear envelope. Generally, $<10 \%$ of the nuclear envelope had these chromatin flecks. The nucleolus was no longer compact, but was more spread out throughout the nucleus. The spreading is primarily a result of decompaction of the pars fibrosa. Mitochondrial cross-sectional diameter was the greatest $(0.69 \pm 0.01 \mu \mathrm{m})$ of all the types of spermatogonia (Fig. 3). The Golgi complexes were positioned in the basal, basolateral and lateral aspects of these cells (Fig. 4).

\section{$A_{3}$ spermatogonia}

$\mathrm{A}_{3}$ spermatogonia were generally similar to $A_{2}$ spermatogonia, but the nucleus of $A_{3}$ cells was slightly different in that between $10 \%$ and $25 \%$ of the nuclear envelope was lined with heterochromatin. The nucleolus was organized loosely and similar to that described for $\mathrm{A}_{2}$ spermatogonia (Fig. 7a,b). The mitochondrial cross-sectional diameter in $\mathrm{A}_{3}$ spermatogonia was large $(0.67 \pm 0.02 \mu \mathrm{m})$ and not significantly different from that of $A_{2}$ cells, but significantly different from other types of spermatogonia (Fig. 3). The 

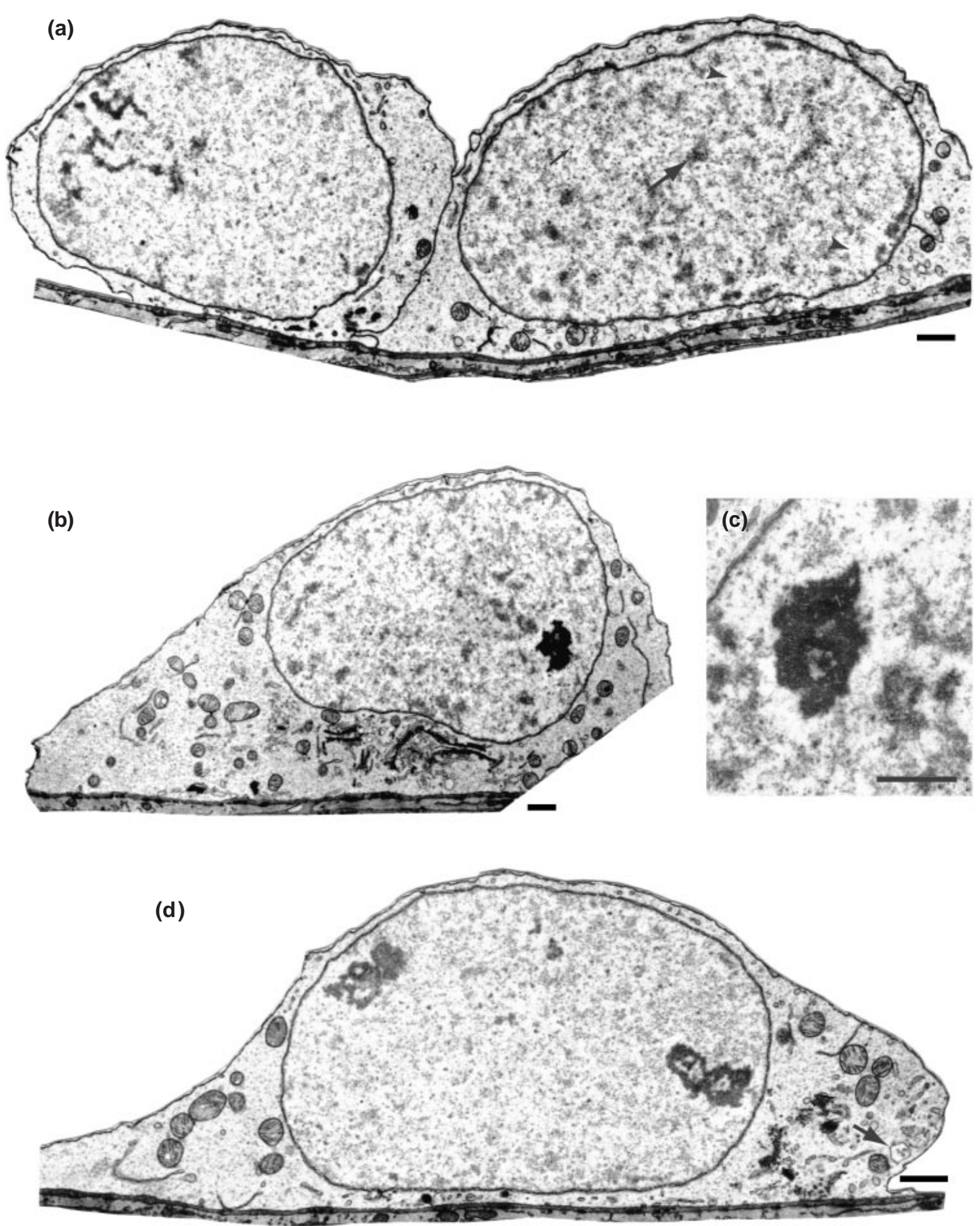

Fig. 5. (a) The cell on the right is an $A_{s}, A_{p r}, A_{a l}$ subtype 2 spermatogonium, whereas the cell on the left is an $A_{3}$ spermatogonium. The former has highly mottled chromatin compared with most of the cells of the $A_{s}, A_{p r}, A_{a l}$ group. Dense flecks of heterochromatin are present throughout the nucleus (small arrow). The moderately dense heterochromatin measures $0.53 \pm 0.02 \mu \mathrm{m}$ across (large arrow) and lies in stark contrast to the rarified nuclear background (arrowheads). The $\mathrm{A}_{3}$ cell is typical of those described below. (b) $A_{s}, A_{p r}, A_{a l}$ subtype 2 spermatogonium is shown with a small compact nucleolus (enlarged in (c)). (d) A transitional spermatogonium. In stage VII, some cells present as intermediate in morphology between those of the $A_{s}, A_{p r}$ and $A_{a l}$ group. The heterochromatin of these intermediate cells shows slight mottling and the nucleus or nuclei are moderately compact. A small (in section) multivesicular body is indicated (arrow). (a) Stage I, (b-d) Stage VII. Scale bars represent $1 \mu \mathrm{m}$. 

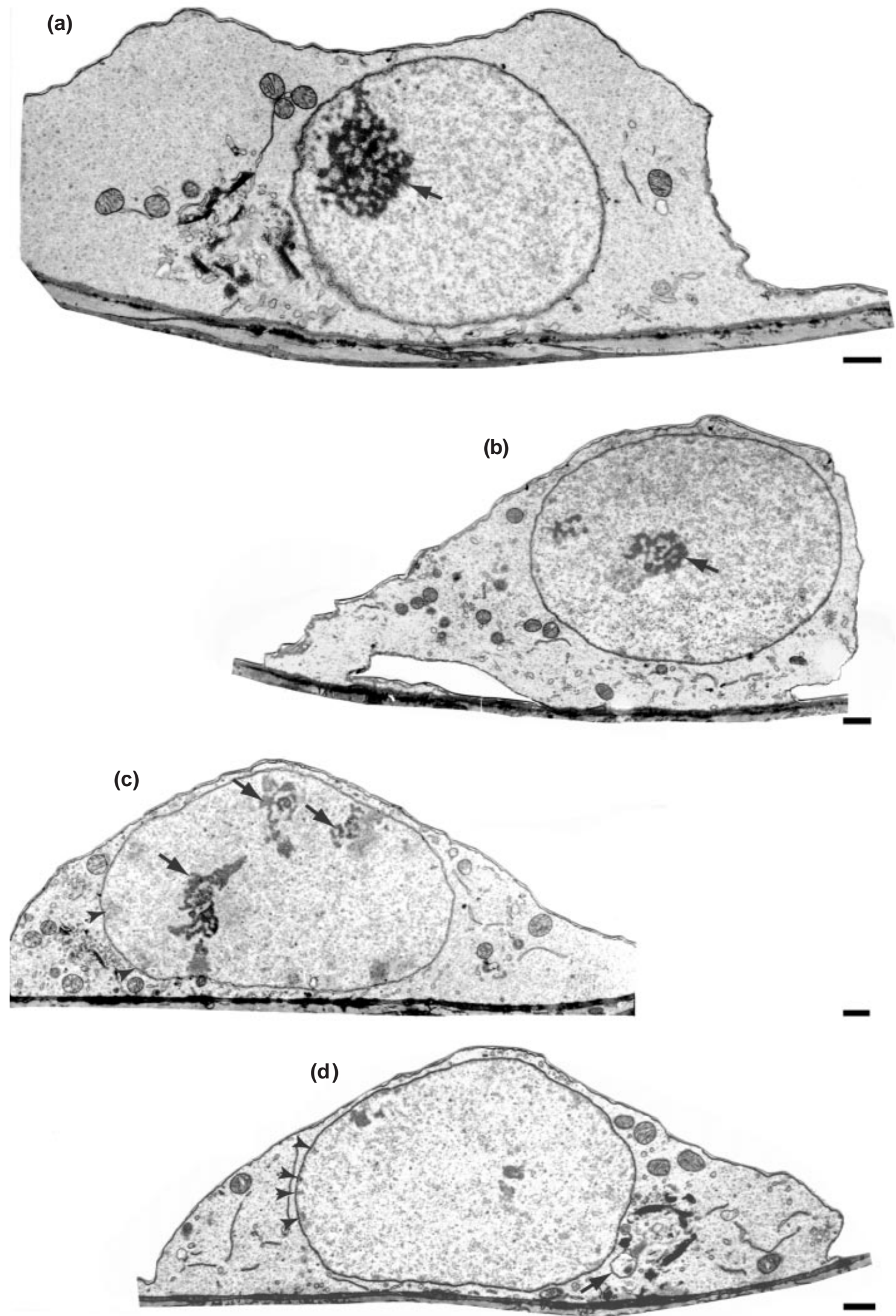

Fig. 6. For legend see facing page. 
Golgi apparatus had a similar (basal, basolateral and lateral) distribution to that of $\mathrm{A}_{2}$ spermatogonia (Fig. 4).

\section{$\mathrm{A}_{4}$ spermatogonia}

The heterochromatin fragments lining the nuclear envelope in $\mathrm{A}_{4}$ cells were larger than those observed in $\mathrm{A}_{3}$ cells. Between $25 \%$ and $40 \%$ of the nuclear envelope was lined with heterochromatin (Fig. 7c,d). The nucleolus was similar to that of $A_{2}$ and $A_{3}$ nucleoli. The mitochondrial cross-sectional diameter in $\mathrm{A}_{4}$ spermatogonia was large $(0.64 \pm 0.01 \mu \mathrm{m})$ and not significantly different from $A_{3}$ spermatogonia, but significantly different from all other types of type A spermatogonia (Fig. 3). The Golgi apparatus was located primarily in the basal, basolateral and lateral regions of the cell (Fig. 4).

\section{Intermediate type spermatogonia}

From $40 \%$ to $90 \%$ of the nuclear margin of intermediate type spermatogonia was occupied by irregularly shaped and low-lying heterochromatin (Fig. 8a,b). The nucleolus was condensed and a pars amorpha and pars fibrosa were clearly visible. The mitochondrial cross-sectional area was markedly and significantly smaller than that of $\mathrm{A}_{4}$ spermatogonia and all other predecessor cells (Fig. 3). The Golgi apparatus was located primarily in the basal, basolateral and lateral regions, although it was found in all locations (Fig. 4). Mitochondrial cross-sectional diameter $(0.47 \pm 0.01 \mu \mathrm{m})$ was significantly smaller than that of all other predecessor types of spermatogonia.

\section{Type $B$ spermatogonia}

In type B spermatogonia, approximately $25 \%$ to $45 \%$ of the rim of the nucleus was heterochromatin (Fig. 8c,d). The shape of the heterochromatin was less irregular than that of the predecessor cells. Instead, generally rounded and more compacted heterochromatin lined the nuclear envelope. Mitochondrial diameters were the smallest of all the categories of spermatogonia $(0.44 \pm 0.01 \mu \mathrm{m})$ and measured significantly less in cross-sectional diameter compared with that of all other groups except for intermediate type spermatogonia (Fig. 3). The Golgi complexes were distributed almost equally around the nucleus, except they were not present at the basal aspect of the cell (Fig. 4). Golgi complexes were located most frequently in the apicolateral and basolateral aspects of the cell. The pars fibrosa of the nucleolus was more compact than the nucleolus of intermediate type spermatogonia (Fig. 8c,d).

\section{Contact with the basal lamina}

The contact of various types of spermatogonia with the basal lamina was measured. The mean \pm SEM $(\mu \mathrm{m})$ contacts are shown: $\mathrm{A}_{\mathrm{s}}$ to $\mathrm{A}_{\mathrm{a}}: 14.02 \pm 2.58(n=4) ; \mathrm{A}_{1}: 14.49 \pm 1.78$ $(n=7) ; \mathrm{A}_{2}: 12.59 \pm 2.61(n=5) ; \mathrm{A}_{3}: 13.29 \pm 1.24(n=17) ;$ $\mathrm{A}_{4}: \quad 11.73 \pm 1.42 \quad(n=12) ; \quad$ intermediate: $9.31 \pm 1.08$ $(n=15)$; and B: $10.07 \pm 1.00(n=9)$. The only significant difference was between $A_{1}$ versus $B$ type and intermediate type spermatogonia.

\section{Side-by-side comparison of spermatogonia}

In some instances, micrographs of different types of spermatogonia were found side-by-side and viewed in the same micrograph. These images make useful comparisons (Fig. 5a) to show differences in spermatogonia. A yes/no decision tree and a brief description of the various types of spermatogonia are shown (Fig. 9).

\section{Discussion}

The present study follows another study using a light microscope in which the various types of spermatogonia were characterized, largely on the basis of nuclear detail (Chiarini-Garcia and Russell, 2001). The results of the present study show that most of the nuclear criteria used for identification of type A spermatogonia with a light microscope also apply at the ultrastructural level.

For example, the relative amount of heterochromatin lining the nucleus is characteristic of specific types of cell; however, the exact percentage of the nuclear envelope with a heterochromatin rim differs in the light and electron microscope studies. The reason for the variance lies in the interpretation of sections of different thicknesses. As the thickness of a section is much greater in light microscope sections than in electron microscope sections, this apparent inconsistency is entirely logical, as structural overlap is greater in thicker sections.

Two characteristics are predominantly responsible for the ability to separate spermatogonia or groups of spermatogonia. Firstly, in the most primitive group of spermatogonia $\left(A_{s}, A_{p r}\right.$ and $\left.A_{a l}\right)$, the mottled appearance of the nucleus is a result of the focal occurrence of moderately dense heterochromatin (although dense heterochromatin flecks are also present) contrasting with regions of no heterochromatin. The mottling slowly goes away in the transition of the primitive group $\left(A_{s}, A_{p r}\right.$ and $\left.A_{a l}\right)$ and is absent in $A_{1}$ spermatogonia. Cells that are more mature than $A_{1}$ spermatogonia show slight mottling, but never to the extent observed in the primitive group.

Fig. 6. (a,b) Type $A_{1}$ mouse spermatogonium. The cells shown contain a finely granular chromatin throughout the nucleus without evidence of mottling. The nucleolus is compact and highly reticulated (arrow). (c,d) Type $\mathrm{A}_{2}$ spermatogonia. Heterochromatin flecks are visible along a small portion $(<10 \%)$ of the nuclear envelope (arrowhead). The chromatin shows fine and dense particles, giving a slightly mottled appearance. The nucleoli (arrows) are stringy and several may be seen in section. (d) A multivesicular body is visible near the Golgi at the lower right of the figure (arrow). (a,b) Stage VII, (c) stage IX and (d) stage X. Scale bars represent $1 \mu \mathrm{m}$. 


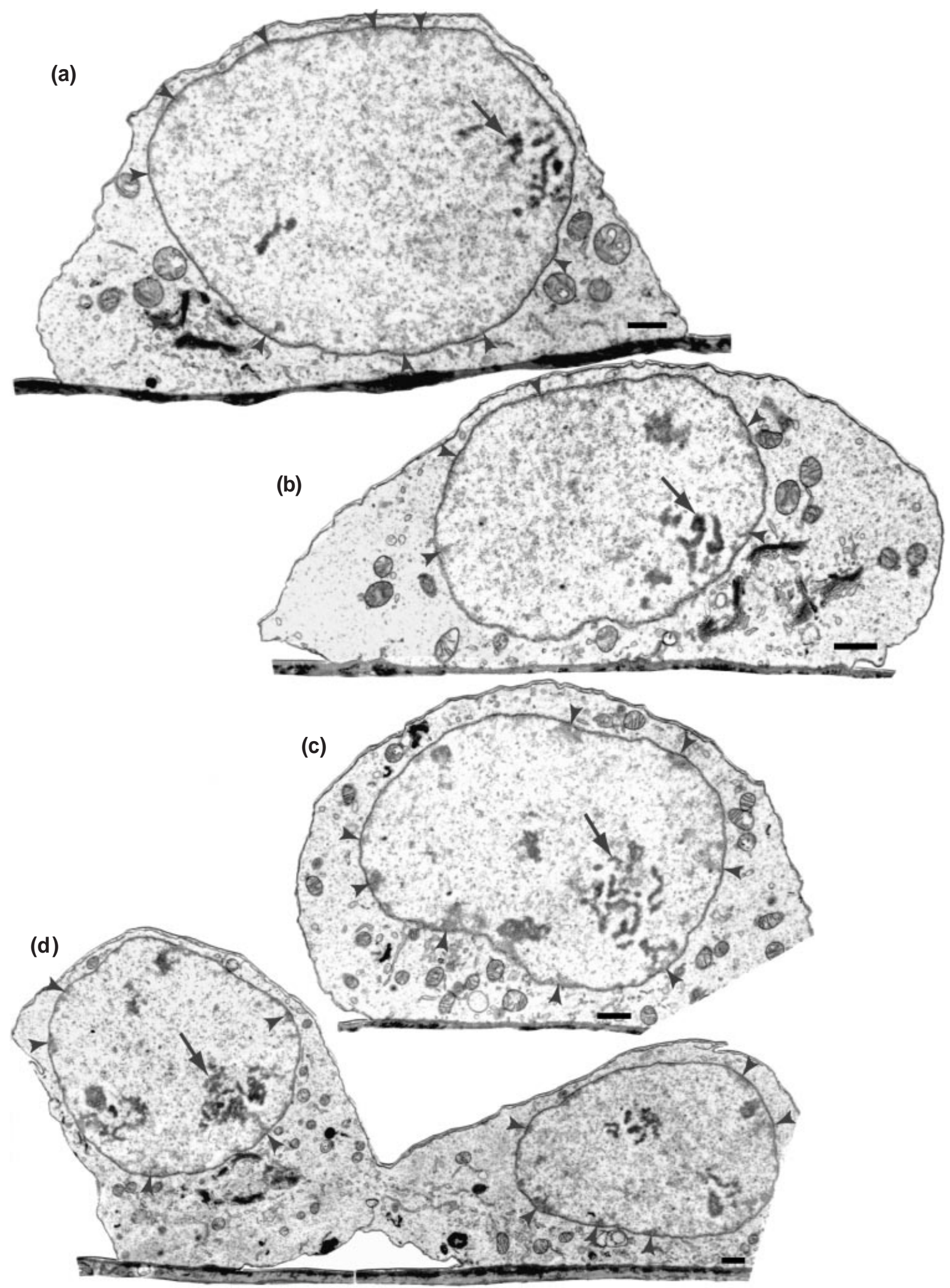

Fig. 7. For legend see facing page. 
(a)

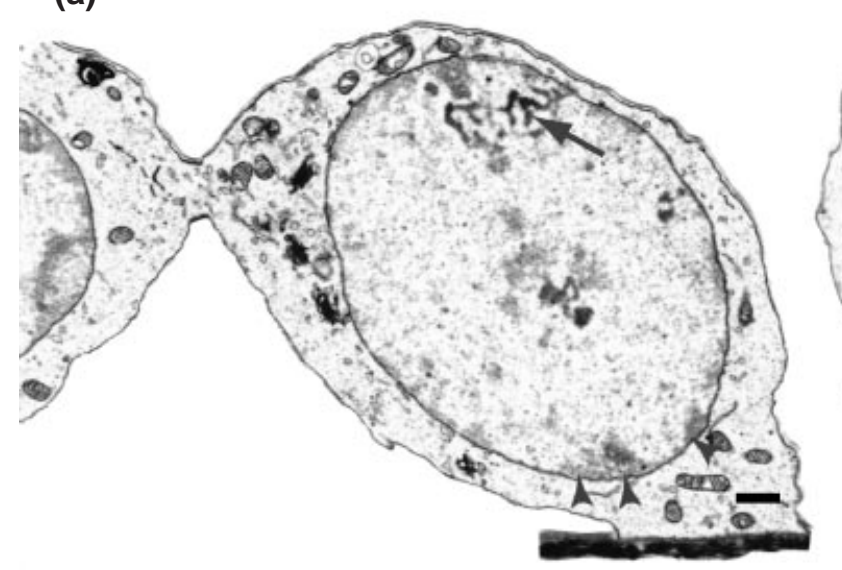

(b)

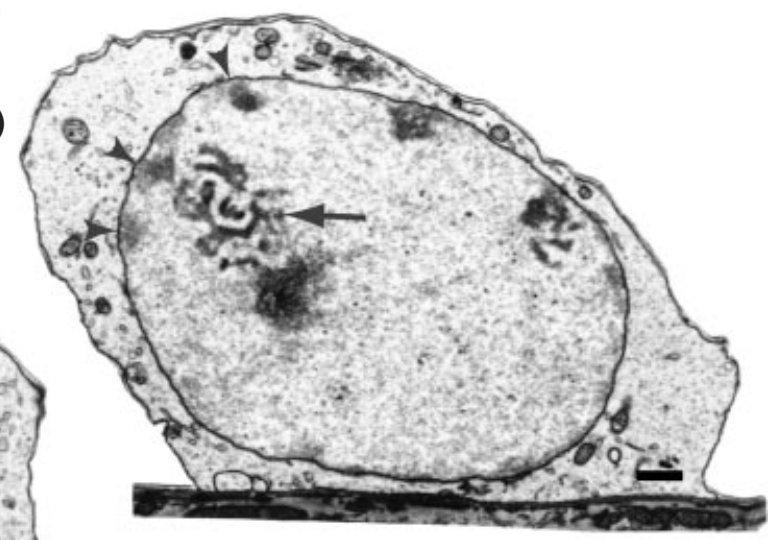

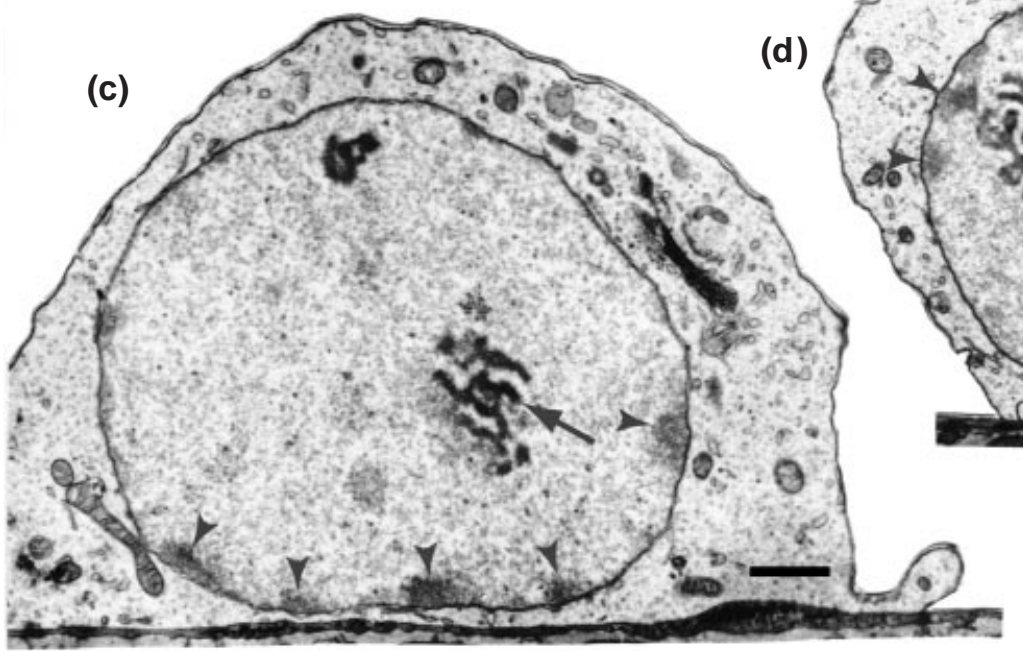

Fig. 8. (a,b) Intermediate type mouse spermatogonia. The nuclei of intermediate spermatogonia have 40-90\% heterochromatin lining the nuclear envelope (arrowheads). The heterochromatin lining the nucleus is generally 'low lying' and the face of the heterochromatin facing the nucleus is highly irregular in shape. The pars fibrosa of the nucleolus (arrow) is loose. $(\mathrm{c}, \mathrm{d})$ Type B spermatogonia. Fewer heterochromatin flecks line the nuclear envelope than in predecessor cells, but they are more prominent. The aspect of the heterochromatin facing the centre of the nucleus is generally rounded (arrowheads). Arrows show the slightly more compact nucleoli than type intermediate spermatogonia. (a,b) Stage IV and (c,d) stage VI. Scale bars represent $1 \mu \mathrm{m}$.

The dense heterochromatin flecks differ in size in different spermatogonia. In the subpopulation of the more primitive spermatogonia $\left(A_{a l}\right.$ subpopulation 2) cells they are the largest $\left(0.53 \mu \mathrm{m}\right.$ across) and are larger than the main $\mathrm{A}_{\mathrm{s},}, \mathrm{A}_{\mathrm{pr}}$ and $A_{a l}$ population $(\leqslant 0.23 \mu \mathrm{m}$ across $)$. The presence of heterochromatin flecks and the increased mottling indicate that the $A_{a l}$ subpopulation 2 may be a separate population of cells from the larger number of $A_{s}, A_{p r}$ and $A_{a l}$, and may represent $A_{s}$ or $A_{p r}$ spermatogonia. Chromatin flecks and mottling are not present in $A_{1}$ cells, but are visible in $A_{2}$ and more mature spermatogonia.

The nuclear vacuole described by light microscopy in the $A_{s}, A_{p r}$ and $A_{a l}$ population of cells by Chiarini-Garcia and Russell (2001) was not observed in the present study, although it was observed in the same tissue by light microscopy. The reason for this difference is not known. Even more puzzling is that nuclear vacuoles were described by electron microscopy by de Rooij (1973).

Fig. 7. (a,b) Type $A_{3}$ mouse spermatogonia. The amount of heterochromatin (arrowheads) lining the nuclear envelope in the two cells shown is approximately $10-25 \%$. The loosely reticulated nucleoli are indicated (arrows). (c,d) Type $\mathrm{A}_{4}$ mouse spermatogonia. The heterochromatin flecks of $\mathrm{A}_{4}$ spermatogonia are considerable larger than those of the predecessor cells. The cells shown have approximately $25-40 \%$ of the nuclear envelope decorated with heterochromatin (arrowheads). Nucleoli (arrows) are reticulated loosely, with the pars fibrosa being the most prominent component. (d) Two conjoined $\mathrm{A}_{4}$ spermatogonia. (a,b) Stage XII, (c) stage II and (d) stage I. Scale bars represent $1 \mu \mathrm{m}$. 


\section{Decision tree for ultrastructural identification of types of spermatogonia}

Does the nucleus have randomly placed foci of moderate amounts of heterochromatin (mottled appearance) measuring about $0.5 \mu \mathrm{m}$ in diameter and at the same time have very little heterochromatin lining the nuclear envelope? Is the nucleolus small and compact with reticulation?
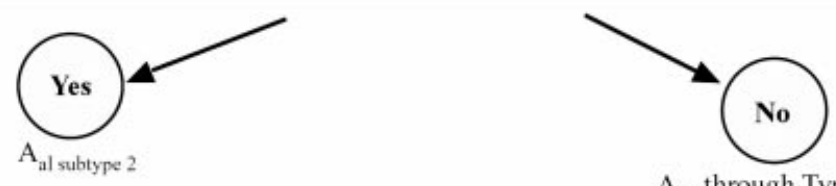

$\mathrm{A}_{\mathrm{al}}$ through Type B

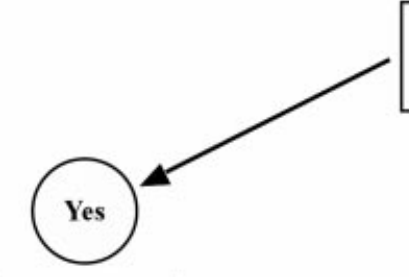

$\mathrm{A}_{\mathrm{al}}$ spermatogonia

Does the nucleus have $0.25 \mu \mathrm{m}$ (in diameter) foci of moderate density heterochromatin?

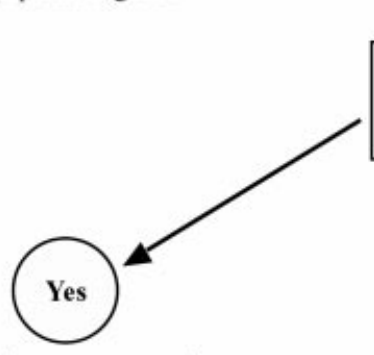

$A_{1}$ through Type B

Is heterochromatin absent along the nuclear envelope and is there a fine euchromatin that is homogeneously granulated?

Type $\mathrm{A}_{1}$ spermatogonia

$\mathrm{A}_{2}$ through $\mathrm{B}$ spermatogonia

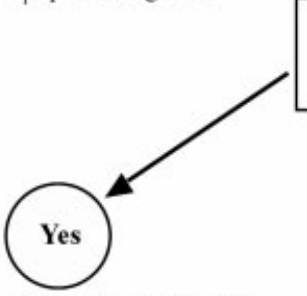

Is $4-40 \%$ of the nucleus lined with heterochromatin? Is the pars fibrosa forming the nucleolus non-compact and spread throughout the nucleus?
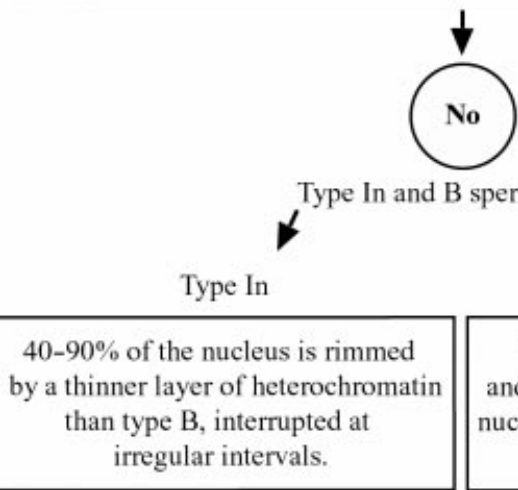

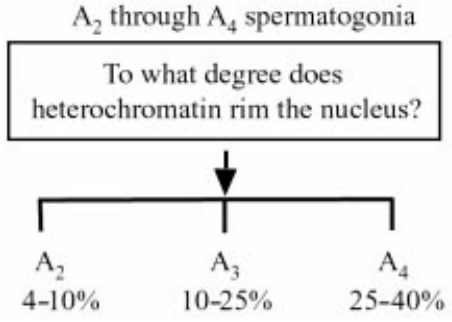

$\mathrm{A}_{2}$ through $\mathrm{A}_{4}$ spermatogonia

To what degree does heterochromatin rim the nucleus?
Heterochromatin is dark, rounded and compact. It protrudes deeply into the nucleus from approximately $25-45 \%$ of the nuclear envelope.

Fig. 9. A yes/no decision tree allows an investigator to determine the type of spermatogonia based on the criteria provided.

The nucleolus is compacted in the primitive $A_{s}, A_{p r}$ and $A_{a l}$ cells. The nucleolus takes a markedly less compacted form after the division to form $A_{1}$ to $A_{2}$ cells. Less compacted nucleoli are considered more active in RNA synthesis (Busch and Smetana, 1970; Schultz and Leblond, 1990). The nucleolar change may be a result of the increased synthetic capacity necessary for the rapid divisions that occur from $A_{2}$ onward. The reason for the apparent 
movement of the Golgi apparatus is not known, but it may be passive as a result of shape changes in the cell or redistribution of its cytoplasm as a result of pressure from surrounding cells.

The results of the present study also demonstrate that differences in organelles were likely to occur in the progress of spermatogonial division. Mitochondrial cross-sectional area increased, reaching a peak diameter in $\mathrm{A}_{2}$ and $\mathrm{A}_{3}$ cells, and then decreased, with the smallest diameter in intermediate and type B cells.

The results relating to the contact of the cell with the basal lamina are limited, as the number of cells was small because most spermatogonia contact with the basal lamina extended beyond the limits of the micrograph. The cells most severely restricted by space were the most primitive cells, as they were more flattened on the basal lamina. Despite these limitations, the data show a trend in which contact is greatest in the most primitive cells and least in the more mature spermatogonia. This is a logical result given that the numbers of cells such as $\mathrm{A}_{4}, \mathrm{~B}$ and intermediate type spermatogonia are confined to a limited space on the basal lamina. As cell populations expand with the latter divisions, either the contact of germ cells or Sertoli cells will be reduced.

The flow chart (Fig. 9) indicates that it may be possible to identify all the major types of spermatogonia at the ultrastructural level. We suggest a certain degree of caution before reaching this conclusion, for several reasons. Firstly, the criteria presented in the present report are developed only for the specified fixation and embedding conditions. Secondly, only sections that capture the central region of the nucleus can be used. Thirdly, all types of spermatogonia cannot be identified unequivocally. For example, the distinction between $A_{3}$ and $A_{4}$ spermatogonia is subtle and errors can easily be made. We suggest that at least three cell types of the same kind should be examined before making a determination.

The present study represents the first attempt to differentiate the various types of spermatogonia, using morphological criteria, at the ultrastructural level. Although many differences in various types of spermatogonia were identified, the differences are subtle and their identification requires considerable effort on the part of the investigator. A major research challenge is to identify and characterize the most primitive of the spermatogonia, especially the $A_{s}$ stem cell. Careful use of the criteria presented above will allow identification of types of cell when performing functional studies of spermatogonia without the necessity of using whole mounts.

The authors acknowledge the NIH (HD 35494 to L. D. Russell and a Latin American Fellowship to H. Chiarini-Garcia) for support of this project. The technical assistance of Angela Raymer and Ying $\mathrm{Li}$ is greatly appreciated.

\section{References}

Busch H and Smetana K (1970) The Nucleus Academic Press, New York

Chiarini-Garcia H and Russell LD (2001) High resolution light microscopic characterization of mouse spermatogonia Biology of Reproduction 65 1170-1178

Chiarini-Garcia H, Hornick JR, Griswold MD and Russell LD (2001) The distribution of Type A spermatogonia in the mouse is not random Biology of Reproduction 65 1179-1185

Clermont $Y$ and Bustos-Obregon E (1968) Re-examination of spermatogonial renewal in the rat by means of seminiferous tubules mounted "in toto" American Journal of Anatomy 122 237-248

de Rooij DG (1973) Spermatogonial stem cell renewal in the mouse. I. Normal situation Cell and Tissue Kinetics 6 281-287

de Rooij DG (1998) Stem cells in the testis International Journal of Experimental Pathology 79 67-80

de Rooij DG (2001) Proliferation and differentiation of spermatogonial stem cells Reproduction 121 347-354

de Rooij DG and Russell LD (2000) All you wanted to know about spermatogonia but were afraid to ask Journal of Andrology 21 776-798

Huckins C and Oakberg EF (1978) Morphological and quantitative analysis of spermatogonia in mouse testis using whole mounted seminiferous tubules. I. The normal testis Anatomical Record 192 519-528

Nagano M, Avarbock MR and Brinster RL (1999) Pattern and kinetics of mouse donor spermatogonial stem cell colonization in recipient testes Biology of Reproduction 60 1429-1436

Oakberg EF (1956) A description of spermiogenesis in the mouse and its use in analysis of the cycle of the seminiferous epithelium and germ cell renewal American Journal of Anatomy 99 391-414

Oakberg EF (1971) Spermatogonial stem-cell renewal in the mouse Anatomical Record 169 515-531

Russell LD and Burguet S (1977) Ultrastructure of Leydig cells as revealed by secondary tissue treatment with a ferrocyanide-osmium mixture Tissue and Cell 9 751-766

Russell LD, Ettlin RA, Sinha Hikim AP and Clegg ED (1990) Histological and Histopathological Evaluation of the Testis Cache River Press, Vienna

Schultz MC and Leblond CP (1990) Nucleolar structure and synthetic activity during meiotic prophase and spermiogenesis in the rat American Journal of Anatomy 189 1-10

Sprando RL (1990) Perfusion of the rat testis through the heart using heparin. In Histological and Histopathological Evaluation of the Testis pp 277-280 Eds LD Russell, RA Ettlin, AP Sinha Hikim and ED Clegg. Cache River Press, Vienna

van Beek ME, Davids JA, van de Kant HJ and de Rooij DG (1984) Response to fission neutron irradiation of spermatogonial stem cells in different stages of the cycle of the seminiferous epithelium Radiation Research $\mathbf{9 7}$ 556-569

van Pelt AMM, van Dissel-Emiliani FMF, Gaemers IC, van der Burg MJ, Tanke HJ and de Rooij DG (1995) Characteristics of A spermatogonia and pre-leptotene spermatocyte in the vitamin A-deficient rat testis Biology of Reproduction 53 570-578

Received 8 October 2001.

First decision 15 November 2001.

Revised manuscript received 13 December 2001.

Accepted 3 January 2002. 